\title{
Efficient Removal of Arsenic from Water by Dielectrophoresis- Assisted Adsorption
}

\author{
Cui.C.Y ${ }^{1,2}$, Chen.H. ${ }^{1,2^{*}}$, Wang. ${ }^{1,2}$, Yang.G ${ }^{1,2}$, Xing.X ${ }^{1,2}$, Li.H ${ }^{1,2}$, Geng.J.F \\ ${ }^{1}$ College of Life and Environmental Science, Minzu University of China, Beijing, China \\ ${ }^{2}$ Beijing Engineering Research Center of Food Environment and Public Health, Minzu University of China, Beijing, China \\ ${ }^{3}$ Institute for Materials Research and Innovation, Institute for Renewable Energy and Environmental Technologies, University of Bolton, Bolton, \\ UK
}

*Corresponding author: Chen.H.Y, College of Life and Environmental Science, Minzu University of China, Beijing, China; Beijing Engineering Research Center of Food Environment and Public Health, Minzu University of China, Beijing, 100081, China; Fax: 008610 68932633; Tel: +8613910159837; E-mail: huiyingrchen@aliyun.com

\begin{abstract}
Adsorption (ADS) and dielectrophoresis (DEP) technique were combined (ADS/DEP) to efficiently remove As (V) in aqueous solution. Fly ash, activated carbon, corncob and plant ash were tested to determine the best adsorbent by their adsorption capacity. Plant ash showed the highest adsorption capacity compared with the others. Different parameters such as solution $\mathrm{pH}$, adsorbent dose were explored. The maximum arsenic removal efficiency was $91.4 \%$ when the $\mathrm{pH}$ was 9.0 and adsorbent dose $5 \mathrm{~g} / \mathrm{L}$ with $7.5 \mathrm{mg} / \mathrm{L}$ initial concentration. With the ADS/DEP technique, the plant ash particles with adsorbed arsenic ions were trapped to the electrodes in a DEP device. The ADS/DEP process can increase the removal efficiency of As (V) to $94.7 \%$ at 14 $\mathrm{V}$ even when the initial concentration of As (V) was $15 \mathrm{mg} / \mathrm{L}$. And the residual concentration of As (V) decreased to $0.34 \mathrm{mg} / \mathrm{L}$ after two series of ADS/DEP process. The adsorbents before and after DEP were examined by a scanning electron microscope (SEM) and energy dispersive X-ray (EDX) analysis. After DEP process, the weight percentage of As (V) on the adsorbents surface increased to $0.96 \%$ from $0.5 \%$. The $\mathrm{ADS} / \mathrm{DEP}$ process could be a new efficient way to remove the arsenic pollutant in water matrices at high concentrations.
\end{abstract}

Keywords: Arsenic removal; Plant ash; Adsorption; Dielectrophoresis
Received date: August 24, 2016

Accepted date: September 10, 2016

Published date: September 15, 2016

Citation: Chen, H.Y., et al. Efficient Removal of Arsenic from Water by Dielectrophoresis-Assisted Adsorption. (2016) J Environ Health Sci 2(2): 1- 4.

DOI: $10.15436 / 2378-6841.16 .1056$

\section{Introduction}

Arsenic is a highly toxic element which has been a serious threat to human health. The sources of arsenic pollution include natural reactions, geochemical reactions, biological activity, volcanic emissions and human activities. However, uncontrolled industrial discharge from mining and metallurgical industries, organo-arsenical pesticides and fossil fuel burning could cause more arsenic pollution to the environment. As reported, long-term exposure to the water polluted by arsenic causes cancers of kidney, liver, bladder, lung and skin. It also leads to chronic health problems such as hyper pigmentation and keratosis of the hands (Smith, A.H., et al 2006). As one of heavy metal pollutant, arsenic has a high toxicity. It is necessary to explore the efficient method to treat arsenic pollution in the waste water.

Several technologies are being developed for the removal of arsenic from water, including chemical oxidation, coagulation with alum and iron, coupled plasma and electrochemistry (Idris, A.O., et al. 2016), nano-filtration, reverse osmosis (Vaclavikova, M., et al 2008, Abejón, A., et al.2015), electro-dialysis (Ali, I., et al.2013), ion exchange (Chiavola, A., et al. 2012), foam flotation (Shafique,U., et al.2012), solvent extraction (Han, B., et al.2002) and adsorption (Ali, I., et al. 2006) using natural and artificial materials. 
Among these techniques, adsorption has been widely used to remove arsenic due to its low cost (Ali, I., et al. 2012) and high efficiency (Abejón, A.,et al.2015). Many materials such as biological materials, mineral oxides, activated carbons (Ali, I., et al. 2010), or polymer resins (Taleb, K., et al. 2015), have been used to remove arsenic. As well known, DEP could cause a motion of dielectric particles caused by polarization effects in a non-uniform electric field (Wakizaka,Y., et al 2004, Hossan, M.R., et al 2013). Moreover, it is a powerful tool which can be used to trap the polarized particles suspended in fluid media in a non-uniform electric field (Rodrigo, M.D. 2012). Furthermore DEP can be used to control the crystal structure and particle size (Cui, C.Y., et al 2015) and morphologies (Cui, C.Y., et al 2016). And we found that heavy metal cation ions can be high effectively removed by combining adsorption and DEP. It is believed that not only cation but also anion ionic pollutants As (V) could be efficiently removed by ADS/DEP. In this study, we first selected plant ash as the adsorbent. After the adsorption process these plant ash particles with As (V) were trapped and removed by DEP. The removal efficiencies of As (V) were investigated under the condition of both ADS and ADS/DEP.

\section{Materials and Methods}

\section{Preparation of adsorbent}

Fly ash (Xuanen, Hubei), activated carbon (Sinopharm Chemical Reagent Co., Ltd), corncob (Tangshan, Hebei) and plant ash (Xuanen, Hubei) were used as the adsorbents. Corncob was mechanically grinded and charring at $800^{\circ} \mathrm{C}$ for $1 \mathrm{~h}$ in the muffle furnace (SX3-4-16, Made in Tianjin).

\section{Adsorption experiments}

The arsenic stock solution of $750 \mathrm{mg} / \mathrm{L}$ was prepared by dissolving the $\mathrm{Na}_{3} \mathrm{AsO}_{4} \cdot 12 \mathrm{H}_{2} \mathrm{O}$ (Sinopharm Chemical Reagent Co., Ltd) salt. All the diluted solutions were prepared by ultra-pure water. Batch experiments were performed with $50 \mathrm{ml}$ or $500 \mathrm{ml}$ of As (V) with the initial concentration $7.5 \mathrm{mg} / \mathrm{L}$ or 15 $\mathrm{mg} / \mathrm{L}$. The stirring time was $1.5 \mathrm{~h}$. The $\mathrm{pH}$ of the solution was adjusted by $0.1 \mathrm{M} \mathrm{HCl}$ or $0.1 \mathrm{M} \mathrm{NaOH}$ solution. The adsorption capacity $\mathrm{q}(\mathrm{mg} / \mathrm{g})$ was calculated from the following equation (1):

$$
q=\frac{(\mathrm{Co}-\mathrm{Ce}) \mathrm{V}}{\mathrm{m}}
$$

Where $\mathrm{Co}$ and $\mathrm{Ce}$ are the initial and equilibrium concentrations of the As solutions, respectively. V is the solution volume (L); $\mathrm{m}$ is the adsorbent mass $(\mathrm{g})$.

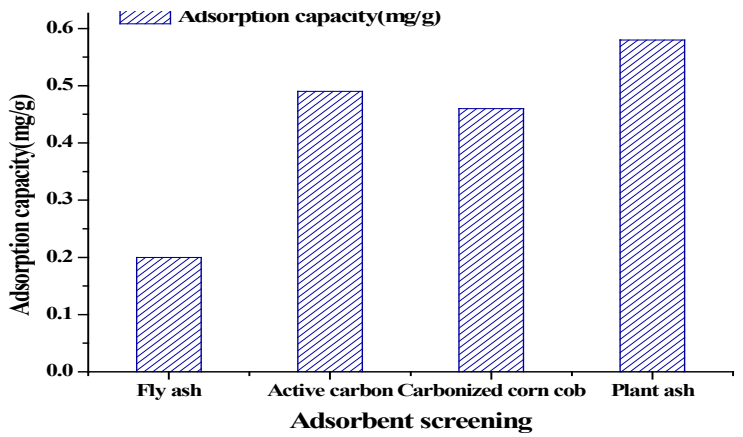

(a)
The concentrations of arsenic in the samples were measured using the water quality-determination of total arsenic-silver diethyldithiocarbamate spectrophotometric method (GB 7485-87). The absorbance of arsenic was tested at the wavelength of $520 \mathrm{~nm}$ by the 721-spectrophotometer (Shanghai analysis instrument Co., Ltd, China).

\section{Dielectrophoresis experiments}

DEP experiments were conducted with a home-made device as shown in Figure 1. (Hu, J., et al 2015). DC voltage was supplied to the electrodes made of titanium wire mesh.

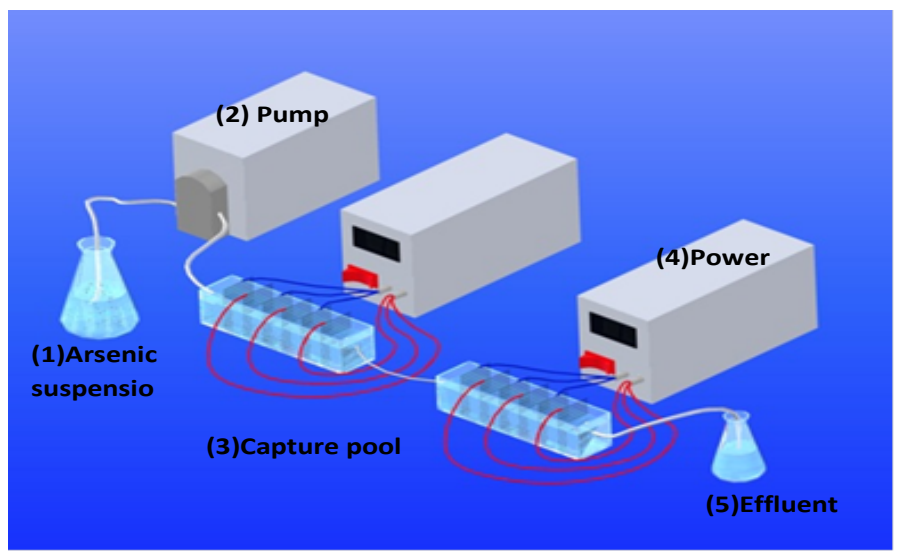

Figure 1: The DEP device layout used in the experiments.

\section{Characterization of adsorbents}

Morphologies of the absorbent samples were examined by a scanning electron microscope (SEM, Hitachi S-4800, Made in Japan). The energy dispersive X-ray (EDX) analysis was used to determine the weight percentage of As on the absorbents.

\section{Results and Discussion}

\section{Screening of the adsorbents}

Fly ash, activated carbon, carbonized corncob and plant ash were tested in the adsorption experiments with the adsorbent $10 \mathrm{~g} / \mathrm{L}$. The stirring time was $1.5 \mathrm{~h}$. Figure. 2(a) shows the adsorption capacity of different adsorbents. It can be observed that the adsorption capacity of As (V) with plant ash $(0.58 \mathrm{mg} / \mathrm{g})$ is the highest among the four adsorbents. It is found that the small particles of the plant ash which is about 10 times smaller compared with the others from Figure. 2(b). These plant ash particles look more spherical in shape, and porous in structure, which are believed to help increase the absorption capacity of As (V). Therefore, plant ash was selected as the adsorbent in the subsequent experiments.

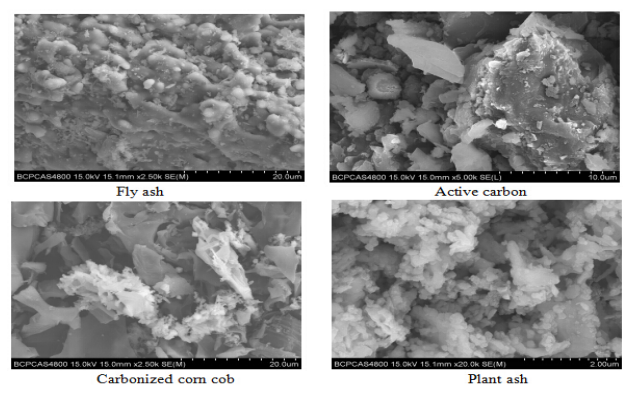

(b) 
Figure 2: Adsorption capacity and morphology of four adsorbents (a) Adsorption capacity of the different adsorbents. (b) SEM micrograph of the different adsorbents

\section{Effect of adsorbent dose}

Effect of the $\mathrm{pH}$ on the adsorption of As (V) onto the plant ash was investigated before we deplored explored the effect of adsorbent dose. It was found that the maximum adsorption took place at $\mathrm{pH}$ 9.0. Therefore, we used $\mathrm{pH} 9.0$ for the subsequent experiments without any adjustment by either base or acid. Provide some basic water chemistry of the water matrix such as EC, turbidity, TDS. Figure. 3 shows the effect of plant ash dosage on the adsorption capacity of As (V) by varying the dose from 2.5 to $15 \mathrm{~g} / \mathrm{L}$ with the initial concentration $7.5 \mathrm{mg} / \mathrm{L}$ at $\mathrm{pH}$ 9.0. It can be observed that the As (V) adsorption capacity by plant ash decreased as the dose increased. While the higher dosage would lead to the total removal rate higher because greater exchangeable sites or more bare surface area could be provided become available at the higher dose [Pandey, P.K., et al 2009]. The total removal efficiency reached $91.4 \%$ when the dosage was $5 \mathrm{~g} / \mathrm{L}$, which was selected as the optimal dosage in the subsequent experiments.

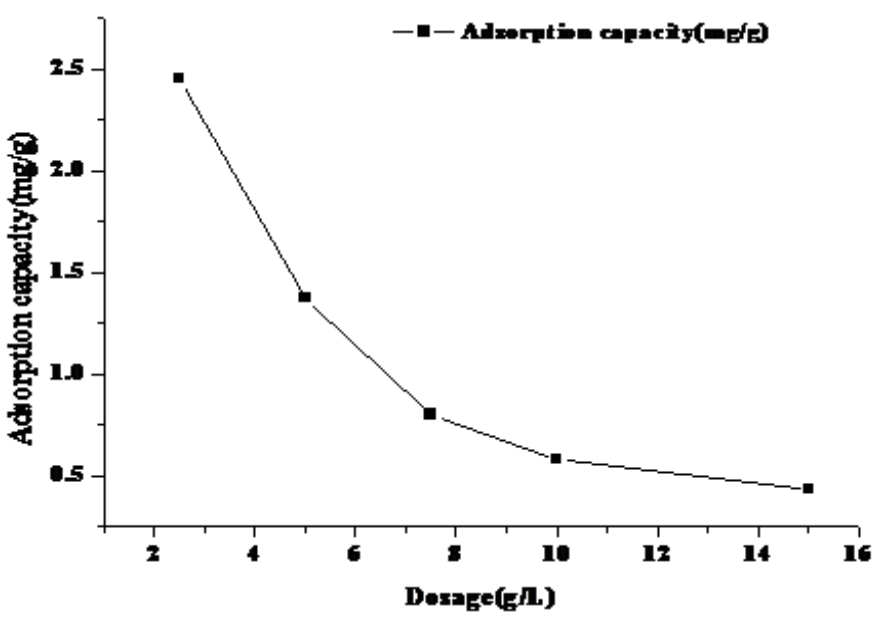

Figure 3: The effect of adsorbent dose on removal of As (V).

\section{Effect of DEP process}

The ADS/DEP experiments were performed with the initial concentration of $15 \mathrm{mg} / \mathrm{L}$ which was a double of the adsorption experiments. After the adsorption of $1.5 \mathrm{~h}$, the suspension was pumped into the DEP device. The voltage was adjusted at $14 \mathrm{~V}$ and the constant flow pump speed at $0.074 \mathrm{ml} / \mathrm{s}$. Figure. 4 shows that the removal rate of As (V) increased significantly after DEP process compared with the adsorption only even if the initial concentration is higher. After two series of ADS/DEP the residual concentration of As $(\mathrm{V})$ was $0.34 \mathrm{mg} / \mathrm{L}$ which was lower than the national industrial standard of China $(0.5 \mathrm{mg} / \mathrm{L})$. The adsorbent particles could be polarized in the electric field and trapped to the electrodes by DEP force which would make the solution clearer. It can be found that the removal rate of As (V) can be significantly improved by combing DEP and ADS. Therefore, we conclude that ADS/DEP can be an efficient way to remove the arsenic pollutant in water.

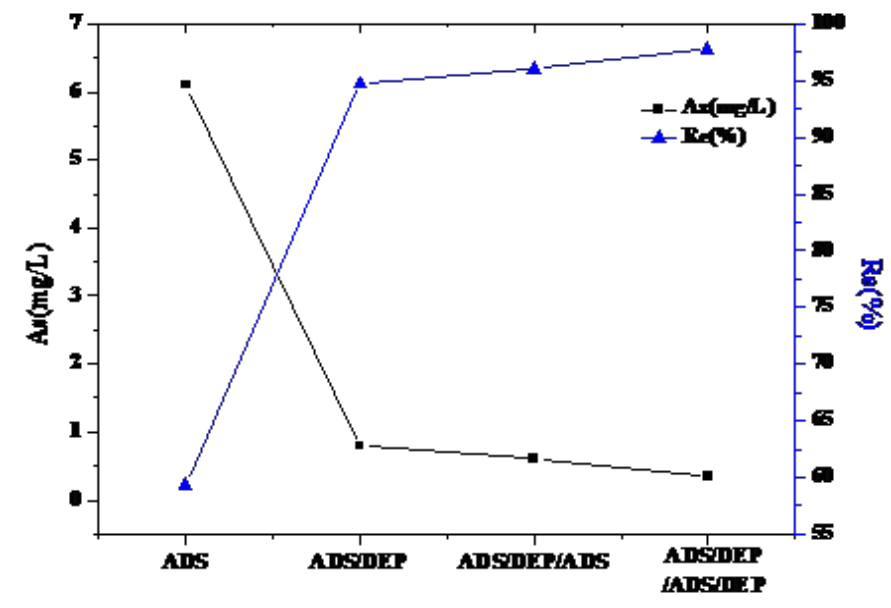

Figure 4: The effect of DEP on the removal rate of As (V).

\section{Analysis of plant ash by SEM and EDX}

Figure 5 shows the morphologies of the plant ash after different processes by SEM. Figure. 5(c) and (d) show that the surface of the plant ash trapped on the electrodes has changed a lot after the DEP process, with a serious aggregation of the particles. The weight percentage of As $(\mathrm{V})$ on the surface of the plant ash before and after the ADS or ADS/DEP process was determined by energy dispersive X-ray (EDX) analysis. The weight percentages of As (V) on the adsorbents increased to $0.96 \%$ and $0.72 \%$ from $0.5 \%$ on the anode and cathode electrodes respectively. It means that the DEP process has greatly facilitated the removal of As (V) from the aqueous solutions.

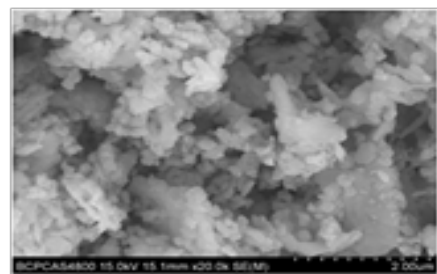

(a)

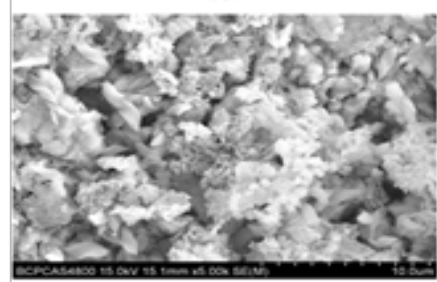

(c)

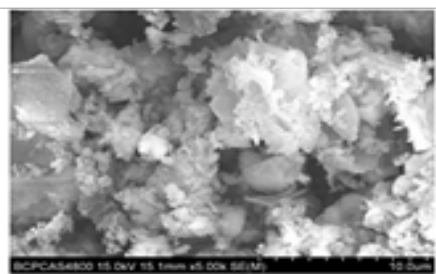

(b)

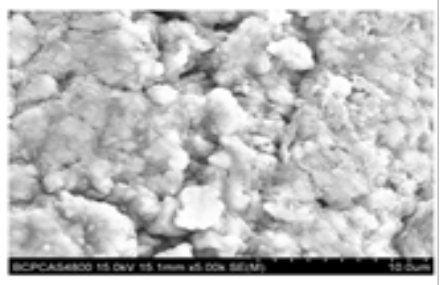

(d)
Figure 5: SEM images of the plant ash

(a) Before ADS, (b) after ADS, (c) after ADS/DEP (anode), (d) after ADS/DEP (cathode)

\section{Conclusions}

To efficiently remove As (V), the plant ash was screened as the best adsorbent in the adsorption experiments. At the optimal conditions, the removal efficiency was $91.4 \%$ when the initial arsenic concentration was $7.5 \mathrm{mg} / \mathrm{L}$. The removal rate of As (V) can be further increased to $94.7 \%$ after DEP process, which was $35.4 \%$ higher than that achieved by adsorption only, when the initial concentration of As (V) was $15 \mathrm{mg} / \mathrm{L}$. In short, our results indicate that the combined ADS/DEP process can be used to greatly improve the removal efficiency of As $(V)$ in aqueous solution compared with the ADS process only. The combined 
approach (ADS/DEP) is hence believed to open up a new avenue towards large scale removal of the anion ionic pollutants (As (V)) in industrial wastewater.

Acknowledgments: This work is supported by "the Fundamental Research Funds for the Central Universities, Innovative academic teams of MUC (NO.2015MDTD25C and 13C), Firstclass university and discipline funds (NO.10301-0150200604), First-class discipline construction project for first-class university of Minzu University of China (YLDX01013) and URTP2014110016.

\section{Reference}

1. Ali, I., Gupta, V.K. Advances in Water Treatment by Adsorption Technology. (2006) Nat Protoc 1(16): 2661-2667.

2. Ali, I. The quest for active carbon adsorbent substitutes: inexpensive adsorbents for toxic metal ions removal from wastewater. (2010) Sep Purif Rev 39(3-4): 95-171.

3. Ali, I., Asim, M., Khan, T.A., Low cost adsorbents for the removal of organic pollutants from wastewater. (2012) J Environ Manag 113: 170-183.

4. Ali, I., Asim, M., Khan, T.A. Aresenite removal from water by electro coagulation on zinc-zinc and copper-copper electrodes. (2013) Int J Environ Sci Technol 10: 377-384.

5. Abejón, A., Garea, A., Irabien, A. Arsenic removal from drinking water by reverse osmosis: Minimization of costs and energy consumption. (2015) Sep Purif Technol 144: 46-53.

6. Chiavola, A., Amato, E. D., Baciocchi, R. Ion exchange treatment of groundwater contaminated by arsenic in the presence of sulphate. Breakthrough experiments and modeling. (2012) Water Air Soil Poll 223(5): 2373-2386.

7. Cui, C.Y., Chen, H.Y., Lan, B.H., et al. Controlled synthesis of $\mathrm{TiO}_{2}$ using a combined sol gel and dielectrophoresis method. (2015) CrystEngComm 17(20): 3763-3767.
8. Cui, C.Y., Chen, H.Y., Zuo, T.T., et al. Controllable synthesis of $\mathrm{TiO}_{2}$ nanoparticles employing substrate/dielectrophoresis/sol-gel. (2016) Cryst Res Technol 51(1): 94-98.

9. Han, B., Runnells, T., Zimbron, J., et al. Arsenic removal from drinking water by flocculation and microfiltration. (2002) Desalination 145(1-3): 293-298.

10. Hossan, M.R., Dillon, R., Roy, A.K., et al. Modeling and simulation of dielectrophoretic particle-particle interactions and assembly. (2013) J Colloid Interf Sci 394: 619-629.

11. Hu, J., Chen, H.Y., Lan, B.H., et al. A dielectrophoresis-assisted adsorption approach significantly facilitates the removal of cadmium species from wastewater. (2015) Environ Sci: Water Res Technol 1(2): 1199-1203.

12. Idris, A.O., Mafa, J.P., Mabuba, N., et al. Dealing with interference challenge in the electrochemical detection of As (III) - A complexometric masking approach. (2016) Electrochem Comm 64: 18-20.

13. Pandey, P.K., Choubey, S., Verma, Y., et al. Biosorptive removal of arsenic from drinking water. (2009) Bioresource Technol 100(2): 634637.

14. Rodrigo, M.D. Microfabrication technologies in dielectrophoresis applications-a review. (2012) Electrophoresis 33(21): 3110-3132.

15. Shafique, U., Ijaz, A., Salman, M., et al. Removal of arsenic from water using pine leaves. (2012) J Taiwan Inst Chem E 43(2): 256-263. 16. Smith, A.H., Marshall, G., Yuan, Y., et al. Increased mortality from lung cancer and bronchiectasis in young adults after exposure to arsenic in utero and in early childhood. (2006) Environ Health Persp 114(8): 1293-1296.

17. Taleb, K., Markovski, J., Milosavljević, M., et al. Efficient arsenic removal by cross-linked macroporous polymer impregnated with hydrous iron oxide: Material performance. (2015) Chem Eng J 279: 66-78.

18. Vaclavikova, M., Gallios, G.P., Hredzak, S., et al. Removal of arsenic from water streams: an overview of available techniques. (2008) Clean Technol Envir Policy 10(1): 89-95.

19. Wakizaka, Y., Hakoda, M., Shiragami, N. Effect of electrode geometry on dielectrophoretic separation of cells. (2004) Biochem Eng J 20(1): 13-19.
Ommega Online Publishers

Journal Title: Journal of Environment and Health Science (JEHS)

Journal Short Name: J Environ Health Sci
Journal ISSN: 2378-6841

E-mail: environmentalscience@ommegaonline.org

Website: www.ommegaonline.org 